\title{
ESTUDO GEOCRONOLÓGICO PELO MÉTODO Rb/Sr EM ROCHAS DO BLOCO JUNDIAÍ E REGIÕES ADJACENTES ${ }^{1}$
}

\author{
EBERHARD WERNICK ${ }^{2}$, MARCOS AURÉLIO FARIAS DE OLIVEIRA ${ }^{3}$, \\ KOJI KAWASHITA ${ }^{3}$, UMBERTO GIUSEPPE CORDANI ${ }^{3}$ e JACQUES DELHAL $^{4}$
}

\begin{abstract}
Field and petrological data, as well as radiometric results performed in granulitic, gnaissic, migmatitic, and granitic rocks from the "Jundiai tectonic block" (States of São Paulo and Minas Gerais), show for that region the existence of two suporposed orogeneses. To the older, of transamazonian age whole rock $\mathrm{Rb}-\mathrm{Sr}$ isochron of $2,010 \mathrm{~m}$.y. $\left(\mathrm{Sr}^{87} / \mathrm{Sr}^{86}\right.$ initial $\left.=0.702\right)$, belongs the Amparo Group, composed of gnaisses, migmatites, and granulites, with intercalation of quartzites, schists and calc-silicate rocks. To the younger, of brazilian age whole rock $\mathrm{Rb}-\mathrm{Sr}$ isochron of 690 m.y. $\left(\mathrm{Sr}^{87} / \mathrm{Sr}^{86}\right.$ initial $\left.=0.706\right)$, are related the feldspathization and migmatization of the Amparo Group, as well as the intrusion of granitic londies. Possibly, also the metassediments around Jacareí belong to the Brazilian cycle. This pattern of geologic evolution is similar to that observed for the Serra dos Orgãos region (States of Rio de Janeiro and Minas Gerais).
\end{abstract}

INTRODUÇÃo A porção oriental do Estado de São Paulo, correspondente à parte do embasamento cristalino que circunda a Bacia do Paraná, é constituída por uma sucessão de blocos crustais com características lito-estruturais distintas, delimitadas por grandes zonas de falhamento. De sul para norte são reconhecidos os seguintes blocos: Costeiro (Coutinho, 1971a e b), que se estende desde a orla maritima até a falha de Cubatão; Juquitiba (Hasui, 1973), delimitado pelas falhas de Cubatão e Caucaia; Cotia (Hasui et al., 1969), situado entre as falhas de Caucaia e Taxaquara; São Roque (Hasui et al., 1969), situado entre as falhas de Taxaquara e Jacutinga; e Pinhal (Penalva e Wernick, 1973), que se estende desde a falha de Jacutinga até o bloco Araxá (Penalva e Wernick, 1973a). Cada um desses blocos tectônicos acha-se, por sua vez, subdividido em unidades menores por falhamentos de menor expressão. Os compartimentos estruturais acima discriminados distinguem-se sob o aspecto litológico e/ou estrutural. Desta maneira a sequiência estratigráfica do embasamento paulista deve ser estabelecida inicialmente num deles e, posteriormente, nos demais blocos adjacentes.

Entre os diversos blocos tectônicos, destaca-se por sua complexidade estratigráfica o Bloco Jundiai onde ocorrem vários grupos de rochas cujas relações no espaço e no tempo ainda não se acham precisamente definidas. Encontram-se na área mencionada os Grupos Amparo, Paraíba, Itapira e Eleutério além de numerosos corpos graníticos com feições litológicas e geológicas muito variáveis. O escopo do presente trabalho é apresentar dados geocronológicos obtidos pelo método $\mathrm{Rb} / \mathrm{Sr}$ referentes a alguns dos mencionados grupos (em particular para os Grupos Amparo e Paraíba, e para as rochas graníticas), além de sua interpretação em estreita correlação com as feições geológicas e petrográficas neles observadas.

\footnotetext{
'Trabalho realizado com auxílio do $\mathrm{CNPq}$

${ }^{2}$ F.F.G.L. de Rio Claro

${ }^{3}$ Instituto de Geociências da USP

${ }^{4}$ Musée Royal de l'Afrique Centrale, Bélgica
} 
GEOLOGIA GERAL Os trabalhos geológicos no Bloco Jundiaí são ainda bastantes esparsos, destacando-se entre eles os de Franco e Coutinho (1957); Wernick (1967 e 1972a, b, c); Wernick e Penalva (1974a, b); Wernick e Artur (1974); e Hasui et al. (1969). O Bloco Jundiaí é constituído por biotiti e/ou hornblenda gnaisses de cor cinzenta, mais ou menos migmatíticos, com intercalaçôes menores de biotita xistos, quartzitos, rochas calco-silicáticas, anfibolitos, gonditos, charnockitos e granulitos ácidos e básicos. Este complexo, informalmente denominado por Ebert (1968) Grupo Amparo e correlacionado, tentativamente, ao Grupo Barbacena, mostra-se cortado por rochas graníticas plutônicas e hipoabissais (granitos, granitos pórfiros, aplitos, pegmatitos). Entre os maciços graníticos que cortam o Grupo Amparo, destacam-se o maciço de Morungaba (Wernick, 1972c; Wernick e Fernandes, 1972), constituído por rochas porfiróides de composição adamelítica associadas a granitos equigranulares róscos a cinzentos. Para o presente trabalho foram coletadas amostras correspondentes aos três tipos mencionados, representados, respectivamente, pelos exemplares JD-154, JD-152 e JD-148 A e B (Fig. 1).

As rochas do Grupo Amparo pertencem às fácies anfibolito e granulito, e apresentam direção regional NE-SW com variações locais para NNE-SSW e ENE-WSW. De modo geral, a inclinação das camadas é elevada, superior a $45^{\circ}$, se bem que localmente possa tornar-se sub-horizontal, como nas imediações de Socorro. O padrão de dobramento é complexo, com grandes dobras fechadas e isoclinais, constituindo anticlinórios e sinclinórios. Os eixos das dobras mergulham de preferência para NE com inclinação em torno de $20^{\circ}$.

Os migmatitos ostentam estruturas que denotam grande plasticidade da rocha por ocasião de sua formação. Assim, são comuns estruturas flebíticas, dobradas, ptigmáticas, schlieren e nebulíticas sendo rara a estrutura agmatítica. Apesar de sinais de elevada plasticidade, os mobilizados graníticos nestas rochas são de âmbito local, nunca atingindo grandes proporções volumétricas. Freqüentemente os migmatitos, que ocupam de preferência os núcleos de anticlinais, passam lateralmente para gnaisses bandados pouco perturbados. Wernick e Penalva (1974a) ressaltam no Bloco Jundiaí dois aspectos importantes para a compreensão da evolução geológica regional: a feldspatização e a migmatização das rochas do Grupo Amparo e, em particular, de rochas granulíticas e charnockíticas. A feldspatização progressiva dessas rochas pode ser observada, passo a passo, ao longo do perfil Socorro (SP)-Munhoz (MG) do qual provêm as amostras JD-164, JD-165-e JD-167. Neste perfil é possível verificar-se que as rochas granulíticas e charnockíticas gradam, por blastese progressiva, para o maciço granítico-migmatítico de Socorro (Wernick e Artur, 1974, Fig. 1). O processo de feldspatização é acompanhado pela progressiva transformação do ortopiroxênio maciço dos charnockitos e granulitos para termos mais fibrosos, e destes para anfibólios, que por sua vez passam sob o efeito de maior adição de potássio, para biotita. $O$ processo é acompanhado pela transformação mais ou menós intensa de ortoclásio em microclínio e da recristalização da rocha com destruição progressiva da textura granulítica. Fenômeno semelhante pode ser observado na rodovia Fernão Dias, nas proximidades de Estiva (MG), exemplificado através da amostra JD-194, proveniente de outra faixa granulítica associada também ao complexo de Socorro. Como exemplo de rocha granulítica não afetada pelo processo metassomático foi coletada a amostra JD-160, correspondente a granulito básico dos arredores de Visconde de Soutelo (Franco e Coutinho, 1957; Wernick, 1967).

A remigmatização dos gnaisses e migmatitos do Grupo Amparo é restrita no Bloco Jundiaí, onde apresenta caráter apenas local. Neste caso, as rochas cinzentas preexistentes são invadidas por um neossoma rosado ou esbranquiçado que retalha o paleossoma, originando estruturas agmatíticas. Com a intensificação do processo as rochas preexistentes 


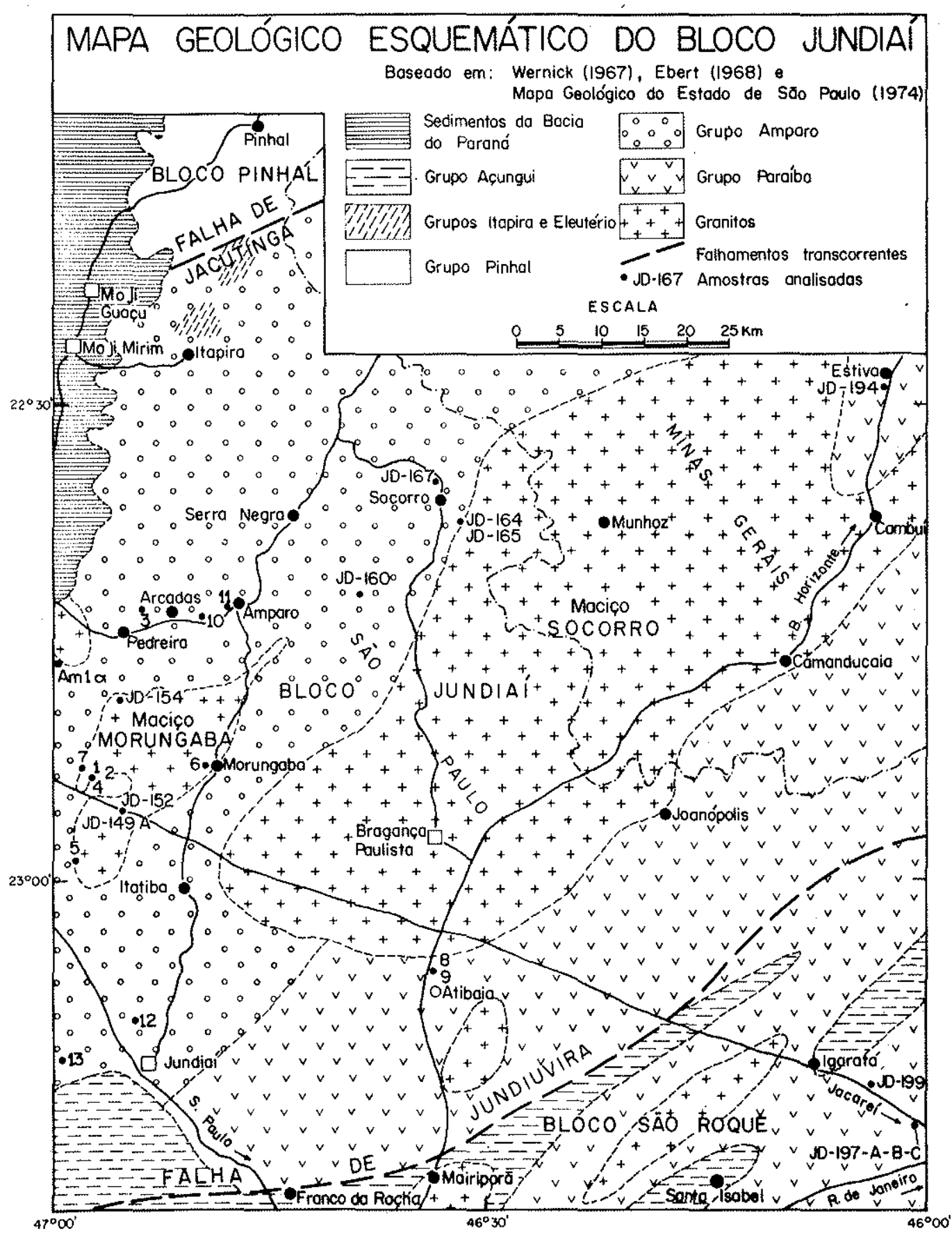

Figura 1 
são progressivamente digeridas e misturadas ao neossoma invasor, originando toda uma gama de estruturas complexas. No caso de o neossoma invadir anfibolitos ocorre a parcial biotitização dos mesmos.

Mais para leste, em direção ao Vale do Paraíba, as rochas do Grupo Amparo são substituídas por rochas referiveis por Ebert (1968, Fig. 1) ao Grupo Paraíba. Visando esclarecer melhor, pelo menos em caráter preliminar, as relaçóes entre os dois citados grupos, os autores coletaram amostras de gnaisses e migmatitos em área mencionada por aquele autor como ocupada pelo Grupo Paraíba, ao longo da rodovia Dom Pedro I. São elas as de número JD-199 e JD-197A, B e C.

Em oposição às rochas do Grupo Amparo, de alto grau de metamorfismo e mais ou menos migmatizadas e remigmatizadas, ocorrem na parte oeste e norte do Bloco Jundiaí metassedimentos pertencentes aos chamados Grupo Itapira (Ebert, 1971) e Eleutério (Ebert, 1971). O Grupo Itapira, que ocorre nos arrestores da cidade homônima, é constituíco por mica xistos, quartzitos, metalarcósios, metabasitos e metacalcários com grau de metamortismo, granulação e infiltrações graníticas menores que as do Grupo Amparo associado. Ebert (1971) considera a estrutura da área em questão formada por um sistema de sinclinais e anticlinais especiais, os primeiros ocupados pelo Grupo Amparo (que considera equivalente ao Grupo Barbacena) e os segundos pelo Grupo Itapira (que considera equivalente aos Grupos São João del Rei e Andrelândia).

Por sua vez, o Grupo Itapira mostra estreita associação com os depósitos molassóides do Grupo Eleutério (Ebert, 1971 e 1974; Wernick e Penalva, 1974b), possivelmente equivalentes à Formação Pouso Alegre (Leonardos Jr. et al., 1971) e a outras formações molassóides cambro-ordovicianas associadas ao Ciclo Brasiliano. O Grupo Eleutério é cons. tituído essencialmente por argilitos vermelhos e arenitos arcosianos, que exibem deformação, resultando numa clivagem tectônica vertical a inclinada, desenvolvida principalmente em parte dos argilitos.

Do acima exposto, conclui-se que o Bloco Jundiaí exibe história geológica complexa na qual é possível discernirem-se pelo menos dois ciclos metamórfico-tectônicos:

1. Um ciclo de médio a alto grau de metamorfismo que envolveu a formação do Grupo Amparo em condições de fácies anfibolito e granulito.

2. Rejuvenescimento posterior através de remigmatização, feldspatização, intrusão de corpos graníticos e, possivelmente, formação dos Grupos Itapira e Eleutério.

Comparando-se as associações litológicas referíveis aos dois ciclos verifica-se que no Grupo Amparo a taxa de metabasitos é superior à do Grupo Itapira, o que implica uma maior contribuição de material infracrustal na constituição daquele. Por outro lado, os fenômenos mais ou menos intensos de remigmatização, feldspatização e intrusão de corpos graníticos associados ao segundo ciclo, sugerem que o mesmo se desenvolveu sob condições de pressóes relativamente baixas e em ambiente bastante hidratado. Finalmente, parte das rochas do Grupo Itapira exibem semelhanças em litologia e grau de metamorfismo com as dos arredores de Jacaré e Igaratá, o que poderia indicar que se trata de rochas cogenéticas (observações de campo efetuadas por um dos autores, E.W.).

RESULTADOS E DISCUSSÃo Tendo em vista que os dados geocronológicos anterior* mente existentes para a região em apreço eram escassos, e obtidos unicamente pelo método K-Ar (Tabela II), de valor interpretativo limitado, foi planejado um programa de determinaçóes $\mathrm{Rb}$-Sr em rocha total em amostras selecionadas adequadamente. Após estudo petrográfico e análises químicas prévias semiquantitativas de $\mathrm{Rb}$ total e $\mathrm{Sr}$ total por fluorescência de raios $\mathrm{X}$, foram escolhidas, para as determinações, três amostras do maciço 
granítico de Morungaba, quatro rochas granulíticas atribuídas ao Grupo Amparo, um granulito da região de Estiva (MG) e quatro amostras de gnaisses e migmatitos das proximidades de Jacareí (SP). Os dados analíticos referentes às determinações efetuadas encontram-se na Tabela I, e os pontos das amostras datadas foram incluídos no diagrama isocrônico da Fig. 2.

As análises Rb-Sr foram realizadas no Centro de Pesquisas Geocronológicas da U.S.P., segundo a metodologia apresentada por Torquato (1974). As concentrações de Rb e de $\mathrm{Sr}$ foram determinadas quantitativamente por fluorescência de raios $\mathrm{X}$, com erros esti-

Tabela I - Dados analíticos Rb-Sr

\begin{tabular}{|c|c|c|c|c|c|c|c|c|}
\hline AMOSTRA & ROCHA & UNIDADE & Rb ppp & Sr tot. ppm & $\mathrm{Rb}^{87} / \mathrm{Sr}^{86}$ & $\mathrm{Sr}^{87} / \mathrm{Sr}^{86}$ & Idade & $\mathrm{Rb}-\mathrm{Sr}^{*}$ \\
\hline JD-149A & Granito cinzo & Mac. Morungaba & 210 & 452 & 1.346 & 0,718 & & - \\
\hline JD-152 & Gran1to róseo & Mac. Morungaba & 150 & 12,4 & 35,88 & 0,956 & 474 & \pm 10 \\
\hline JD-154 & Granito porfiró1de & Mac. Morungaba & 280 & 168 & 4,85 & 0.749 & 616 & \pm 34 \\
\hline JD-160 & Granulito básico & Grupo Amparo & 2.4 & 88,0 & 0,079 & 0.703 & & - \\
\hline JD-164 & Enderbito & Grupo Amparo. & 92,0 & 420 & 0,634 & 0.714 & & - \\
\hline JD-165 & Gna1sse granulftico & Grupo Amparo & 93,2 & 148 & 1,858 & 0,762 & 2060 & \pm 80 \\
\hline$J D-167$ & B1ot. gna1sse & Grupo Amparo & 134,0 & 52,5 & 7.54 & 0.915 & 1870 & \pm 40 \\
\hline JD-194 & Enderb1to & Grupo Parafba & 113,0 & 232 & 1.414 & 0,738 & 1580 & \pm 110 \\
\hline Jo-197A & Blot.gna1sse faco1dal & Grupo Parafba & 310 & 228 & 3.95 & 0.745 & 685 & \pm 41 \\
\hline JD-1978 & B1ot.gna1sse faco1dal & Grupo Paraf́ba"N" & 248 & 277 & 2,60 & 0.733 & 729 & \pm 60 \\
\hline JD-197C & Gran. biot. gna1sse & Grupo Parafba" nn" & 236 & 265 & 2.58 & 0.732 & 712 & \pm 61 \\
\hline JD- 199 & Gnaisse granitico & Grupo Parafba "A* & 384 & 123 & 9.12 & 0.799 & 695 & \pm 22 \\
\hline$A M-1 a^{* \star}$ & Granito gnä1ssico & Grupo Amparo & 187 & 160 & 3,40 & 0.745 & 796 & \pm 47 \\
\hline
\end{tabular}

'com R. L. $=0,705$

-em Cordanie Kawashita (1971), recalculado

- de acordo com o mapa apresentado por Ebert (1968), Fig. 1

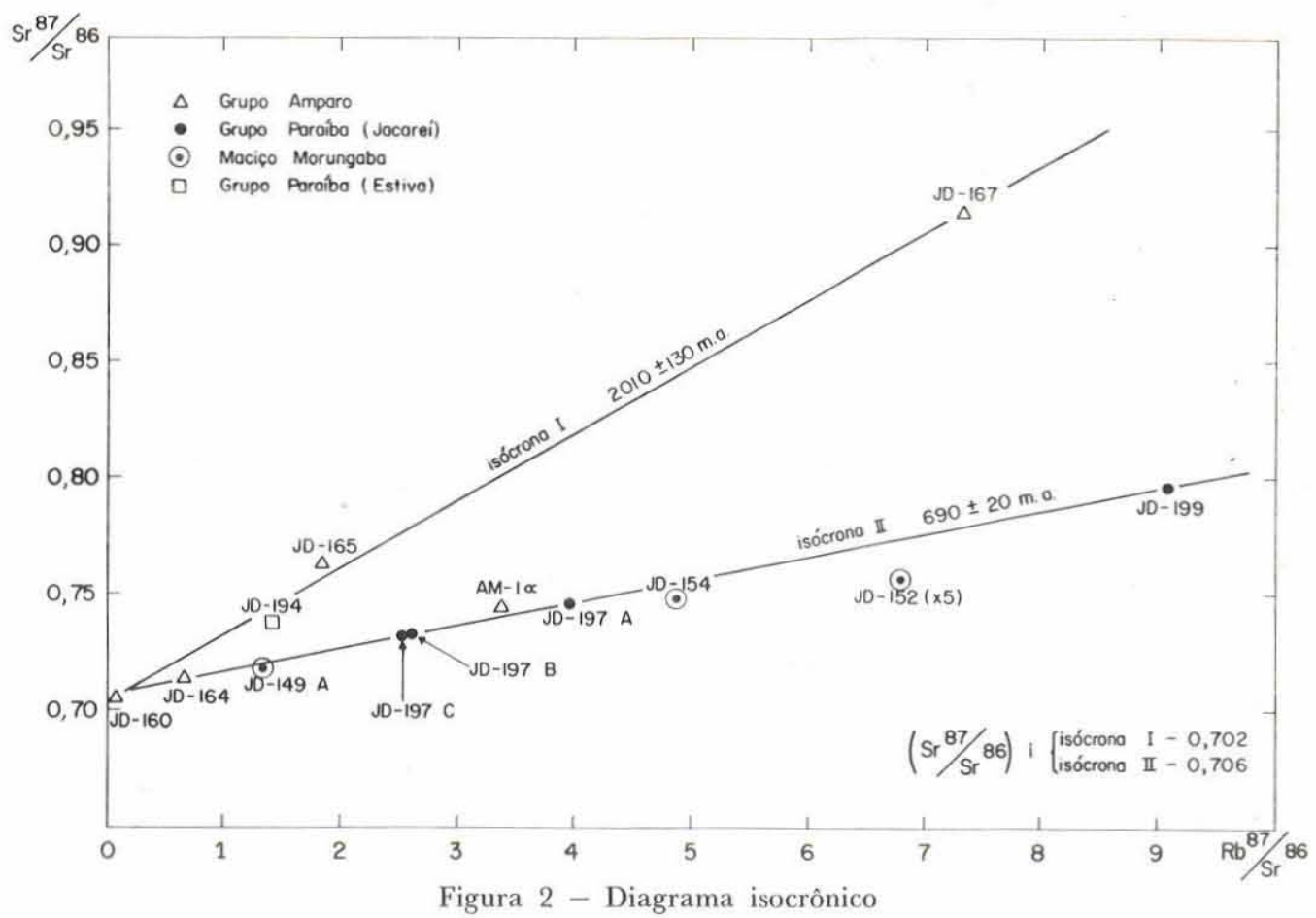


mados inferiores a $3 \%$. As relaç̃̃es $\mathrm{Sr}^{87} / \mathrm{Sr}^{86}$ foram obtidas em espectrômetro de massa Varian-MAT tipo TH-5, estando sujeitas a erro experimental inferior a $0,3 \%$. No período em que foram realizadas as determinações, 36 análises no carbonato de estrôncio Eimer Amend apresentaram valor na razão $\mathrm{Sr}^{87} / \mathrm{Sr}^{86}$ de $0,7082 \pm 0,0006(2 \sigma)$. Nos cálculos de idade, foi utilizado o valor de $\lambda_{\mathrm{Rb}}=1,47 \times 10^{-11} \mathrm{anos}^{-1}$.

Todas as idades $\mathrm{K}-\mathrm{Ar}$ da região (Tabela II) representam valores mínimos para a formação das respectivas rochas, e a maioria deles é característica do Ciclo Brasiliano, demonstrando a importância deste na evolução geológica regional. Pelo menos uma delas (amostra de n. ${ }^{0}$ 13) apresenta idade K-Ar claramente pré-Brasiliana, desde já demonstrando a existência de rochas regionais formadas em épocas anteriores. Não é possivel, a partir dos dados K-Ar, revelar as épocas pré-Brasilianas significativas na formação de rochas.

Tabcla II - Dados analíticos das determinações K-Ar disponíveis

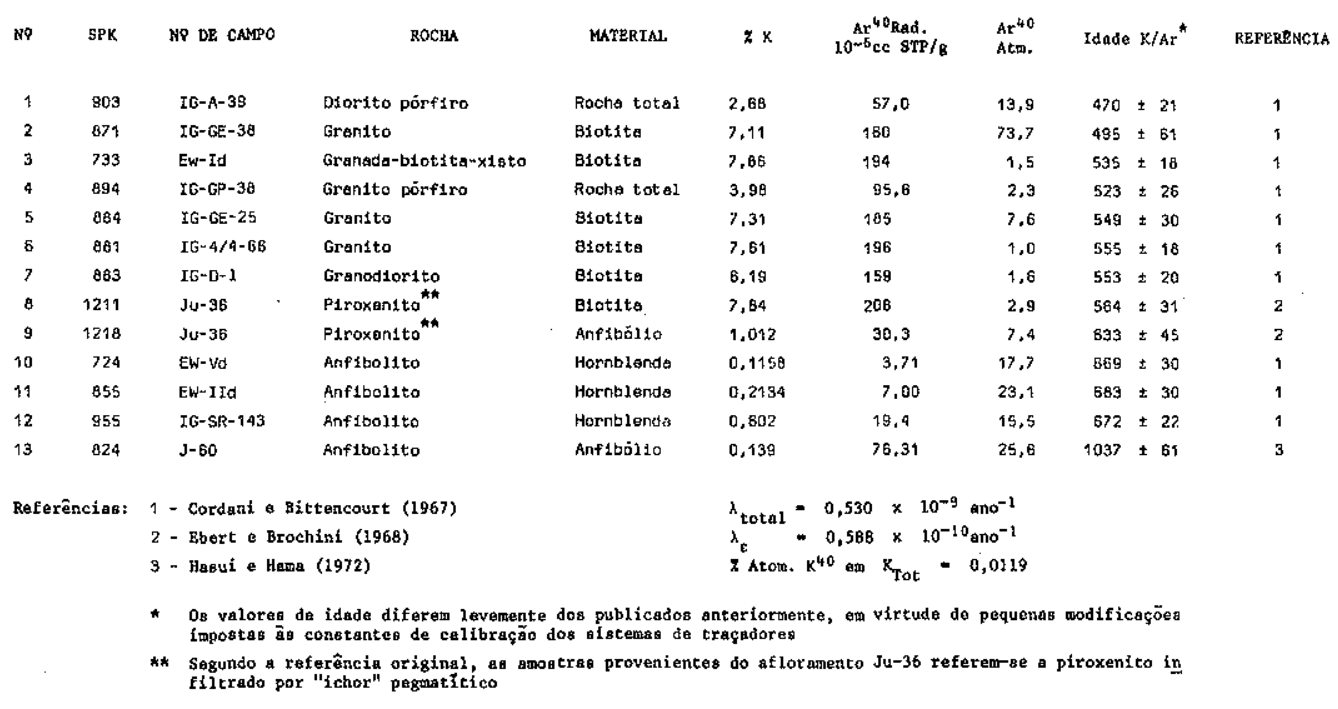

As amostras JD-160, JD-165 e JD-167, pertencentes ao Grupo Amparo, situam-se nas proximidades da isócrona de referência de 2010 m.a., com razão inicial $\mathrm{Sr}^{87} / \mathrm{Sr}^{86} \cong$ $\cong 0.70$ 2 (isócrona I). Embora com apenas três pontos, eles estão dispersos adequadamente no diagrama isocrônico, o que nos permite sugerir o Ciclo Transamazônico para a época de formação das rochas gnáissicas e granulíticas do Grupo Amparo. O granulito básico JD-160 controla a razão inicial da isócrona, cujo valor relativamente baixó torna pouco provável uma história crustal das rochas analisadas anterior ao Ciclo Transamazônico. Por outro lado, a amostra JD-167 controla a inclinação da reta, conferindo-lhe significativa precisão. Outro granulito atribuído ao Grupo Amparo (amostra JD-164) apresentou ponto analítico na Fig. 2 abaixo da isócrona I e sobre a isócrona $\mathrm{II}$, o que provavelmente significa total rejuvenescimento durante o Giclo Brasiliano, aliado a metassomatismo potássico. $\mathrm{O}$ mesmo pode ter ocorrido para o granito gnáissico $\mathrm{AM}-1 \alpha$, dos arredores de Pedreira, cuja caracterização e análise Rb-Sr aparecem em Cordani e Kawashita (1971).

Finalmente, a amostra JD-194, o granulito de Estiva (MG), que pertence à área de ocorrência do Grupo Paraíba de Ebert (1968), possui ponto analítico situado logo abaixo da isócrona I, sugerindo co-geneticidade com o Grupo Amparo, e rejuvenescimento apenas parcial no Ciclo Brasiliano. 
A fase sintectônica do Giclo Brasiliano, com idade entre 650 e 700 m.a., já verificada em trabalhos anteriores (Almeida et al., 1973), parece estar perfeitamente evidenciada pelas análises das amostras JD-197A, B, G e JD-199 cujos pontos analíticos definem a isócrona II da Fig. 2. Das quatro amostras desta isócrona, que consideramos co-genéticas, três provêm de um mesmo afloramento (JD-197A, B e C). A razão inicial $\left(\mathrm{Sr}^{87} / \mathrm{Sr}^{86}\right.$ ) desta isócrona, 0,706, é normal para material granítico-gnáissico do Ciclo Brasiliano, metamorfoseado em fácies anfibolito. Os dados $\mathrm{Rb}$-Sr parecem indicar tratar-se de material formado no próprio Ciclo Brasiliano, por metamorfismo de sedimentos sincrônicos aos do Grupo Açungui, em grau mais elevado. Material mais antigo, com vida crustal anterior, certamente apresentaria razão $\left(\mathrm{Sr}^{87} / \mathrm{Sr}^{86}\right)_{i}$ mais elevada. Entretanto, as descrições petrográficas das amostras envolvidas mostram claramente a formação de feldspatos potássicos e moscovita em porfiroblastos posteriores à paragênese metamórfica primária das rochas. Se tal processo foi acompanhado de entrada de $\mathrm{K}$ e $\mathrm{Rb}$ nos sistemas em quantidades consideráveis e se a quantidade inicial de $\mathrm{Rb}$ era muito pequena, é possível imaginar a evolução geológica regional a partir da existência de rochas anteriores, afetadas intensamente por metassomatismo alcalino durante o Ciclo Brasiliano.

Com relação às amostras do maciço de Morungaba, as três determinações efetuadas encaixam-se no padrão geocronológico já evidenciado em outros lugares (Cordani e Kawashita, 1971; Cordani et al., 1974), na faixa de dobramentos Ribeira. Amostras de tendência alcalina, equigranulares, de coloração rósea, tal como acontece na amostra JD-152, apresentam idades da ordem de $470 \mathrm{~m}$.a. ligadas às fases finais do ciclo orogênico. Amostras de caráter granodiorítico e/ou adamellítico, de colorações diversas com predominância de tonalidades de cinza, situam-se sobre isócronas de referência mais antigas, tal como ocorre neste caso. A idade convencional da amostra JD-154, que se apresenta favorável para determinações $\mathrm{Rb}-\mathrm{Sr}$, é da ordem de $620 \mathrm{~m}$.a., considerando-se $\left(\mathrm{Sr}^{87} / \mathrm{Sr}^{86}\right)_{i}=$ $=0,705$. Isto parece indicar, uma vez mais, a evolução petrogenética complexa dos maciços graníticos, como o de Morungaba, com duração de várias dezenas de milhões de anos.

CONSIDERAÇOES SOBRE A EVOLUÇÃO GEOLOGICA REGIONAL A análise integrada dos dados geológicos, petrográficos e geocronológicos disponíveis para o Bloco Jundiaí permite delinear, pelo menos em caráter preliminar, a seguinte evolução geológica:

1. Metamorfismo regional no Ciclo Transamazônico agindo sobre material supra e infracrustal, em condições de fácies anfibolito e granulito, resultando na formação do Grupo Amparo, constituído essencialmente por gnaisses e migmatitos cinzentos com intercalações de granulitos, xistos, gonditos, rochas calco-silicáticas e quartzitos. (Isócrona de 2010 m.a., com razão inicial $\mathrm{Sr}^{87} / \mathrm{Sr}^{86}=0,702$.)

2. Metamorfismo regional no Ciclo Brasiliano, com remigmatização, feldspatização e intrusão de corpos graníticos. O neossoma granítico dos migmatitos formados neste evento é predominantemente róseo. Durante esta fase, o Grupo Amparo foi rejuvenescido em caráter mais ou menos intenso, como 'c demonstrado pela existência de rochas com idade intermediária entre os ciclos Transamazônico e Brasiliano.

Com relação às amostras provenientes da região de Jacareí, os resultados $\mathrm{Rb} / \mathrm{Sr}$ sugerem tratar-se de material formado no Ciclo Brasiliano (isócrona de 690 m.a., com $\left.\left(\mathrm{Sr}^{87} / \mathrm{Sr}^{86}\right)_{i}=0,706\right)$. Entretanto, não pode ser excluída a hipótese de tratar-se de material mais antigo, completamente rejuvenescido neste ciclo.

Pelo exposto, o padrão geocronológico regional exibe paralelismo marcante com aquele obtido para a região da Serra dos Orgãos (Cordani et al., 1973). O Grupo Amparo 
mostra-se inteiramente correlacionável ao Grupo Paraíba enquanto as rochas graníticas (Maciço Morungaba e manifestações associadas) guardam correlação completa com a "Formação Serra dos Orgãos". Torna-se inviável a correlação entre os Grupos Amparo e Barbacena, tal como sugerido por Ebert (1968).

Finalmente, cabem ainda duas considerações de caráter regional, sugeridas pelos dados geocronológicos obtidos aliados às observações geológicas que vêm sendo obtidas sistematicamente:

1. As rochas de fácies granulito que foram analisadas (Grupo Amparo) apresentam idades antigas, mantendo uma vez mais a observação de que, até o presente, não são conhecidas no Brasil rochas granulíticas seguramente referiveis ao Ciclo Brasiliano. 2. Observando-se a quantidade de material granítico na região estudada em função de sua idade, nota-se que o mesmo apresenta comportamento diferencial. Assim, nas litologias transamazônicas, o material granítico é mais raro restringindo-se, via de regra, a mobilizados locais mais ou menos restritos. Já nas formações de idade brasiliana o material granítico é abundante sob a forma de profuso neossoma em migmatitos, além de freqüentes maciços de dimensões batolíticas. Este fato, observado em muitas regióes da Plataforma Brasileira sugere que o Ciclo Brasiliano se caracteriza particularmente por agregar à crosta abundante material granítico quer por adição a partir do manto quer pela reciclagem de material crustal mais antigo.

\section{APENDICE}

JD-149

Granito (Maciço Morungaba)

Rodovia D. Pedro I, km 112

$\mathrm{Mi}-\mathrm{Qz}-\mathrm{Pl}-\mathrm{Bi}-\mathrm{Cl}-\mathrm{Op}$

Rocha cinzenta maciça. Textura granular hipidiomórfica a xenomórfica. Granulação média. Rica em titanitas eu-hedrais. Plagioclásios zonados. Os restos maiores de microclínio são ricos em inclusões de plagioclásio.

JD-152

Granito (Maciço Morungaba)

Rodovia D. Pedro I, km 117

$\mathrm{Mi}-\mathrm{Qz}-\mathrm{Pl}-\mathrm{Mu}$

Rocha rósea, equigranular, maciçaı. Lexturiı granular, hipautomórfica a xenomórfica. Granulação rósea. Leves sinais de cataclase local. A moscovita se resume a alguns grãos menores.

JD-154

Granito porfiroblástico

Arredores de Entremontes, $10 \mathrm{~km}$ a $\mathrm{SW}$ de Pedreira

$\mathrm{Mi}-\mathrm{Qz}-\mathrm{Pl}-\mathrm{Bi}-\mathrm{Op}$

Rocha cinzenta com megacristais róseos de microclínio, maciça. Textura inequigranular, hipautomórfica. Granulação grosseira a média. Megacristais envolvendo restos de plagioclásio e quartzo. Biotita rica em halos pleocróicos e com posição intersticial entre os minerais siálicos. Plagioclásio com núcleo sericitizado.

JD- 160

Granulito básico

Arredores da Estação Ferroviária Visconde de Soutelo, às margens do Rio Gamanducaia, $20 \mathrm{~km}$ a SW de Socorro

Pl-Gr-Di-Hip-Hb-Qz-Op

Cor preta esverdeada, maciça, Rocha muito compacta. Textura granoblástica, hipautomorfica, 
granulação média. Freqüente textura poiquiloblástica (hornblenda-granada; plagioclásio-piroxênio) e estrutura em coroa das granadas. (Granada envolvida por anel de plagioclásio. Reação piroxênio $\rightarrow$ $\rightarrow$ anfibólio.)

JD-164

Granulito ácido. Enderbito

Estrada Socorro-Munhoz, $2 \mathrm{~km}$ a E de Socorro

Pl-Qz-Mi-Hip-Au-Bi-Op

Quartzo recristalizado formando leitos de grandes cristais alongados. Relações indicando piroxênio $\rightarrow$ anfibólio $\rightarrow$ mica. Rocha cinza-esverdeada-escura, foliada. Textura granular, hipautomórfica a xenomórfica, parcialmente cataclástica (moagem e encurvamento dos planos de geminação do plagioclásio). Inequigranular grosseira a fina.

JD-165

Gnaisse granulítico cataclástico

Estrada Socorro-Munhoz, $2 \mathrm{~km}$ a E de Socorro

Pl-Or-Mi-Qz-Bi-Op

Rocha foliada de cor cinza. Textura granolılástica, xenomórfica parcialmente cataclástica. Granulação fina. Microclinização do ortoclásio. Cioncentração de biotita nos planos de cisalh.amento. Incipiente recristalização nos planos de maior concentração de movimentos.

JD-167

Biotita gnaisse

Rodovia Socorro-Itapira, a $3 \mathrm{~km}$ de Socorro

Mi-Qz-Pl-Ep-Bi-Op

Rocha cinza foliada. Textura cataclástica e cisalhada. Granulação fina, cristais esmagados, curvados e fraturados.

JD-194

Granulito (enderbito)

Rodovia São Paulo-Belo Horizonte (Fernão Dias), km 411

Pl-Bi-Hip-Qz-Op-Gr

Rocha preta-esverdeada, maciça. Textura granoblástica, hipautomórfica. Granulação média.

JD-197 A

Biotita gnaisse facoidal

Rodovia D. Pedro I, km 7

$\mathrm{Pl}-\mathrm{Qz}-\mathrm{Bi}-\mathrm{Mu}-\mathrm{Hb}-\mathrm{Op}-\mathrm{Gr}-\mathrm{Mq}$

Rocha cinzenta levemente foliada, com megacristais de microclínio. Textura porfiróide, com megacristais de feldspato alcalino rico em inclusões de biotita e quartzo, e parcialmente envolvidos por cristais de biotita. Matriz de granulação média a fina em parte cataclástica, recristalizada, xenomórfica.

JD-197 B

Biotita gnaisse facoidal

Rodovia D. Pedro I. km 7

Qz-Pliıg-Mi-Bi-Op

Rocha cinzcuta …m megactist.tis abundantes de feldspato alcalino róseo. Textura porfiróide com megacristais de microclínio com abundantes inclusões de quartzo e plagioclásio. Matriz fina a média. Xenomórfica, cataclástica, parcialmente recristalizada.

JD-197 C

Granada-biotita gnaisse

Rodovia D. Pedro I, km 7

Mi-Qz-Bi-Gr-Pl-Op

Rocha cinzenta, levemente foliada. Textura inequigranular com esparsos cristais maiores de micro- 
clínio envolvidos por cristais menores de biotita e minerais siálicos. Inclusões concentradas nos bordos dos megacristais. Sinais de cataclase e recristalização. Granulaçào lina a média.

JD-199

Gnaisse granítico (moscovita quartzito feldspático)

Rorlovia D. Pedro I, km 17

$\mathrm{Bi}-\mathrm{Pl}-\mathrm{Mu}-\mathrm{Gr}-\mathrm{Qz}-\mathrm{Mi}$

Roxha cinza clara, foliada. Textura granular xenomórfica, orientada, com leitos ora enriquecidos em quartzo (parcialmente recristalizado, formando grandes cristais alongados) feldspato ou moscovita. Porfiroblastos de moscovita. Granulação média predominante.

\section{BIBLIOGRAFIA}

ALMEIDA, F.F.M. de, AMARAL, G., CORDANI, U. G, e KAWASHITA, K. - 1973 - The Precambrian Evolution of the South American Cratonic Margin, South of the Amazon River, in: Nairn, A. G. M. e Stehli, F. G. (eds.), The Ocean Basin and Margins, Vol, 1, Cap. 11, 411-446

CORDANI, U.G. e BITTENCOURT, I. - 1967 - Determinações de idade potássio-argônio em rochas do Grupo Açungui. An. XXI Congr. Bras. Geol., 218-233

CORDANI, U.G. e KAWASHITA, K. - 1971 - Estudo geocronológico pelo método Rb-Sr de rochas graníticas intrusivas no Grupo Açungui. An. XXV Congr. Bras. Geol., 105-110

CORDANI, U. G., DELHAL, J. e LEDENT, D. - 1973 - Orogenèses superposées dans le Precambrien du Brèsil sud-oriental (États de Rio de Janeiro et de Minas Gerais). Rev. Bras. Geoc. 3, $1-22$

CORDANI, U. G., HALPERN, M. e BERENHOLC, .1. - 1974 - Comentários sobre as determinaçðes geocronológicas da Folha de Porto Alegre. In: Carta Geológica do Brasil ao Milionésimo, DNPM Folhas de Porto Alegre (SH-22) e Lagoa Mirim (SI-22), 70-84

GOUTINHO, J. M.V. - 1971a - Pré-Cambriano Paulista: Parte l - Pré-Cambriano ao sul da cidade de São Paulo. XXV Congr. Bras. Geol., Boletim Especial n. ${ }^{\circ}$ 2, Roteiro das excursões, $53-62$

COUTINHO, J. M. V. - 1971b - O falhamento de Cubatão. XXV Congr. Bras. Geol. Resumo das Comunicações. Boletim Especial n. ${ }^{\circ}$ 1, 130-131

EBERT, H. - 1968 - Ocorrências da fácies granulito ao sul de Minas Gerais e em áreas adjacentes, em dependência da estrutura orogênica: hipóteses sobre sua origem. An. Acad. Brasil. Giên., 40. Suplemento, 215-229

EBERT, H. - 1971 - Os Paraibides entre São João Del Rei, Minas Gerais, e Itapira, São Paulo, e a bifurcação entre Paraibides e Araxaides. XXV Congr. Bras. Geol., Boletim Especial n. ${ }^{\circ} 1$, Resumo das Comunicaçðes, $177-178$

EBERT, H. - 1974 - O Grupo Eleutério e a falha de Jacutinga (Nordeste de São Paulo). XXVIII Congr. Bras. Geol., Boletim Especial n. ${ }^{\circ}$. Resumo das Comunicaçðes, 726-730

EBERT, H. e BROCHINI, M.F. - 1968 - Estudos estratigráficos e geocronológicos no Escudo Cristalino Brasileiro. Ciência e Cultura 20,621-625

FRANCO, R. R. e COUTINHO, J. M. V. - 1957 - Charnockitos e rochas associadas no Município de Amparo e Socorro, Estado de São Paulo. An. Acad. Bras. Ciên. 28, 303-311

HASUI, Y. - 1973 - Tectonica da área das folhas de São Roque e Pilar do Sul. Tese de Livre-Docência. Instituto de Geociências da Universidade de São Paulo, 190 pp. (inédito)

HASUI, Y., PENALVA, F. e HENNIES, W. T. - 1969 - Geologia do Grupo São Roque. An. XXIII Congr. Bras. Geol., 101-134

HASUI, Y. e HAMA, M. - 1972 - Geocronologia do Grupo São Roque pelo método potássio-argónio. Rev. Bras. Geociên. 2, 8-24

LEONARDOS Jr., O.H., DUNHAM, A. G., MENDES PIRES, F. R. e FORMAN, J. M. A. 1971 - Nota sobre a formação Pouso Alegre. An. Acad. Brasil. Cien. 43, 131-134

PENALVA, F. e WERNICK, E. - 1973 - Compartimentação tectônica em parte do Pré-Cambriano paulista. XXVII Congr. Bras. Geol., Resumo das Comunicações. Boletim n. ${ }^{\circ} 1,128-129$ 
PENALVA, F. e WERNICK, E. - 1973a - Feições estruturais de migmatitos ao norte e sul da falha de Jacutinga, Leste do Estado de São Paulo. Ciência e Cultura 25, 183

TORQUATO, J. R. - 1974 - Geologia do Sudoeste de Moçâmedes e suas relações com a evolução tectônica de Angola. Tese de Doutoramento. Instituto de Geociências da Universidade de São Paulo, 243 pp. (inédito)

WERNICK, E. - 1967 - Geologia da região de Amparo (leste do Estado de São Paulo). Tese de Doutoramento. F.F.C.L. de Rio Claro. 225 pp. (inédito)

WERNICK, E. - 1972a - Sobre a ocorrência de rochas calco-silicáticas nas proximidades de Duas Pontes, Município de Arcadas, Leste do Estado de São Paulo. Ciência e Cultura 24, 358-367

WERNICK, E. - 1972b - Granitos pórfiros dos arredores de Serra Negra, Valinhos e Amparo e suas relações com o maciço de Morungaba, Leste do Estado de São Paulo. Rev. Bras. Geociên. 2, 129-138

WERNICK, E. - 1972c - A geologia do maciço granítico de Morungaba, Leste do Estado de São Paulo. Escola de Engenharia de São Carlos. Boletim Geologia 16, 110 pp.

WERNICK, E. e FERNANDES, N. A. - 1972 - Triclinicidade de feldspatos potássicos de rochas graníticas do maciço de Morungaba, SP. An. XXVI Congr. Bras. Geol., Vol. 1, 51-56

WERNICK, E. e PENALVA, F. - 1974a - Migmatização e feldspatização de charnockitos e granulitos no leste paulista e sul de Minas Gerais. XXVIII Congr. Bras. Geol. Resumo das Comunicações, 445-448

WERNICK, E. e PENALVA, F. - 1974b - Depósitos molassóides da formação Eleutério, São Paulo-Minas Gerais. XXVIII Congr. Bras. Geol. Resumo das Comunicações, 723-726

WERNICK, E. e ARTHUR, A. C. - 1974 - Petrofábrica de migmatitos dos arredores de Amparo, SP. Rev. Brasil. Geociên. 4, 27-39 